\title{
Comparison of dynamic hip screw and proximal femoral nail in the treatment of Intertrochanteric fracture of femur
}

\author{
Samant P.D. ${ }^{1}$, Kale S.Y. ${ }^{2}$, Singh S.D. ${ }^{3}$, Chaudhary P. ${ }^{4}$, Dhar S.B. ${ }^{5}$, Gohain N.K. ${ }^{6}$ \\ ${ }^{1}$ Dr Prakash D Samant, Professor and Head, ${ }^{2}$ Dr Sachin Y Kale, Professor, ${ }^{3}$ Dr Shikhar D Singh, Senior Registrar, ${ }^{4}$ Dr Prasad \\ Chaudhari, Associate Professor, ${ }^{5}$ Dr Sanjay B Dhar, Professor, ${ }^{6}$ Dr Nabakrishna Gohain, Registrar, all authors are affiliated \\ with Department of Orthopaedics, Padmashree, Dr DY Patil Medical College, Navi Mumbai, India.
}

Address for Correspondence: Dr. Shikhar D Singh, Senior Registrar, Department of Orthopaedics, Padmashree Dr DY Patil Medical College, Navi Mumbai. Email: drsinghshikhar@gmail.com

\begin{abstract}
Introduction: As the elderly population grows, the number of hip fractures continues to increase. This study aims to compare the clinical outcomes of DHS and PFN in the fixation of intertrochanteric fracture of femur. Methodology: After obtaining approval of the ethics committee, a prospective study was conducted in the Department of Orthopedics, DY Patil School of Medicine from January 2014 till December 2015. Informed consent was taken from from patients who fulfilled the inclusion/exclusion criteria and relevant clinical information was collected, including intra and post-operative details. The patients were called for followup to check for complications. Results: During the study period, 50 patients with intertrochanteric fracture were included in the study, of which 23 were treated ith PFN and 27 with DHS. $76 \%$ of the PFN patients needed no blood transfusion, while $41 \%$ of DHS patients needed 2 units of blood transfusions. Post operative fever and deep vein thrombosis was more common in DHS patients. $79 \%$ of PFN patients started mobilizing on the first postoperative day as compared to $68 \%$ of DHS patients who starting mobilizing on third postoperative day. Similarly post operative weight, full weight bearing and return to activity of daily living was seen to be better in PFN patients. Conclusions: Our study showed that PFN is a superior method of osteosynthesis as compared to DHS in the treatment of intertrochanteric fractures. Future research should focus on studying the economic and rehabilitative impact of PFN on patients with intertrochanteric fractures.
\end{abstract}

Keywords: Complications, Dyanamic hip screw, Intertrochanteric fracture

\section{Introduction}

As the elderly population grows, the number of hip fractures continues to increase. Worldwide, the total number of hip fractures is expected to surpass 6 million by the year 2050 [1]. The elderly have weaker bone and are more likely to fall due to poorer balance, medication side effects, and difficulty maneuvering around environmental hazards and hip fractures substantially increase the risk of death and major morbidity in this age group.

These risks are also high among nursing home residents, particularly men, patients over age 90, those with cognitive impairment and other comorbidities, individuals treated nonoperatively, and those who cannot ambulate independently. A large review of hip fractures in the United States found that femoral neck and intertrochanteric fractures occur with approximately the

Manuscript Received: $8^{\text {th }}$ December 2016

Reviewed: $16^{\text {th }}$ December 2016

Author Corrected: $23^{\text {rd }}$ December 2016

Accepted for Publication: $31^{\text {st }}$ December 2016

International Journal of Surgery \& Orthopedics same frequency in patients between the ages of 65 and 99 years [2]. However, isolated trochanteric fractures occur more often in young, active adults between the ages of 14 and $25[2]$.

In order for a patient with an intertrochanteric fracture to return to activity as soon as possible and to avoid the complications associated with non-ambulatory treatment, internal fixation of these fractures has been accepted as the standard procedure. To achieve this goal a variety of implants for internal fixation have been employed with variable success. Among these Dynamic hip screws (DHS) and Proximal Femoral Nail (PFN) are one of the most successful fixation devices employed in stabilizing these fractures [3]. These implants provide secured fixation and controlled impaction of the fracture with lower rate of complications. Using DHS \& PFN, excellent results have been achieved with majority of patients having simple intertrochanteric fractures. However there 


\section{Original Research Article}

remained many unsolved problems in the acceptability of these implants in unstable intertrochanteric fractures. Failure rates are higher up to $8 \%$ to $25 \%$ with unstable fracture patterns [4] and as high as $50 \%$ in most unstable fractures [5].

This study aims to compare the results of DHS and PFN in the fixation of intertrochanteric fracture of femur in terms of radiological union, early mibility and weight bearing and complications. We also wanted to evaluate functional outcome in both the grous using the Modified Harris Hip Score.

\section{Methodology}

Study design and setting- We designed a prospective study at the Department of Orthopedics, DY Patil School of Medicine from January 2014 till December 2015. We included patients who were aged 21 years or more, had closed intertrochanteric fractures with other joints of lower limbs in functionally good state. We excluded patients who were not medically fit to undergo surgery, had a previous surgery for fracture fixation in the lower limbs, had an open fracture or severe comminuted fractures or refused to give consent to be included in the study. We also excluded patients who had iplsilateral or contralateral major limb injury affecting the treatment or rehabilitation process.

Data collection and analysis- After giving first aid to patients arriving at the trauma center, routine investigations were performed. Basic radiological investigations pertaining to that of fracture sustained were done in addition to the standard trauma series of investigations. After the initial management, all patients were assessed for any medical ailment and patients were managed accordingly. Informed consent was taken from all patients. All patients were explained about the perceived advantages of proximal femoral nail and the additional cost of the implant. Stable patients were taken up for surgery at the earliest after the pre anaesthetic evaluation. Mobilization of patients was started on or after second post operative day depending upon the pain and general condition of the patient. Exercises in the form of static quadriceps, knee bending were started. Intra venous antibiotics were administered for 72 hours post surgery and oral antibiotics were continued until 3 days post removal of sutures.

Patients were sent home after suture removal. Patients were followed up in the out patients department monthly for up to six months then three monthly. On every visit local site was examined for any signs of local inflammation or infection, range of motion at the hip joint was assessed, and both anteroposterior and lateral radiographs were taken of the hip joint to look for the progress of union.

Partial weight bearing walking with walker was started (toe touch walking) once patient had regained quadriceps control and straight leg raising and radiographic signs of callus formation were seen. Full weight bearing walking was started once radiographic signs of union have occurred.

During the course of treatment, clincial information of the patient regarding age, gender, mode of injury, previous medical history, amount of blood loss, complications were collected. We classified the patients according to Boyd and Griffin Classification and AO Classification [6] [7].

AO Classification catagorizes injuries according to their location and severity. After the start of rehabilitative process, appearance of late complications, information regarding physiotherapy and overall clinical outcome using Modified Hip Score was noted for each patient [8].

This score rates the clinical outcome in terms of pain, gait and functional activities. The data were compiled in mocrosoft excel sheets and analysed using appropriate statistical analysis. The descrptive variables were tabulated and both the techniques for managing intertrochanteric fractures were compared.

\section{Results}

During the study period, 50 patients with intertrochanteric fracture were included in the study, of which 23 were treated ith PFN and 27 with DHS. 52\% of PFN and $27 \%$ of DHS patients were males (Table 1). Majority of the patients had fall as the mode of injury. $41 \%$ of PFN belonged to Boyde \& Griffin Classification III and 68\% of DHS belonged to Boyde \& Griffin Classification II. All DHS patients belonged to AO classification 31 A1 (Table 2). 28\% of the patients who underwent PFN had blood loss less than $100 \mathrm{ml}$, while $18 \%$ of the patients who had DHS had blood loss between 100-300 $\mathrm{ml}$. 76\% of the PFN patients needed no blood transfusion, while $41 \%$ of DHS patients needed 2 units of blood transfusions. Post operative fever and deep vein thrombosis was more common in DHS patients (Table 2). 79\% of PFN patients started mobilizing on the first postoperative day as compared to $68 \%$ of DHS patients who starting mobilizing on third postoperative day. Similarly post operative weight, full weight bearing and return to activity of daily living was seen to be better in PFN patients (Table 2). Modified Hip scores of patients of both categories is given in Table 3. 
Original Research Article

Table-1: Characteristics of patients included in the study.

\begin{tabular}{|c|c|c|}
\hline Patient variable & Proximal Femoral Nail & Dynamic Hip Screw \\
\hline$n$ & 23 & 27 \\
\hline \multicolumn{3}{|c|}{ Age distribution (in years) } \\
\hline $40-50$ & 10 & 3 \\
\hline $51-60$ & 5 & 3 \\
\hline $61-70$ & 5 & 43 \\
\hline $71-80$ & 8 & 4 \\
\hline $81-90$ & 3 & 9 \\
\hline \multicolumn{3}{|c|}{ Gender distribution } \\
\hline Male & 12 & 22 \\
\hline Mode of injury & 21 & 5 \\
\hline Fall & 2 & 16 \\
\hline Road traffic accident & Associated medical history & 11 \\
\hline Hypertension/Diabetes & 12 & \\
\hline None & 11 & \\
\hline
\end{tabular}

Table-2: Pre- and post-operative details of the patients.

\begin{tabular}{|c|c|c|}
\hline Patient variable & Proximal Femoral Nail & Dynamic Hip Screw \\
\hline$n$ & 23 & 27 \\
\hline \multicolumn{3}{|c|}{ Boyde \& Griffin Classification } \\
\hline $\mathrm{I}$ & 0 & 9 \\
\hline II & 6 & 18 \\
\hline III & 10 & 0 \\
\hline IV & 7 & 0 \\
\hline \multicolumn{3}{|c|}{ AO Classification } \\
\hline $31 \mathrm{~A} 1$ & 0 & 27 \\
\hline $31 \mathrm{~A} 2$ & 8 & 0 \\
\hline $31 \mathrm{~A} 3$ & 15 & 0 \\
\hline \multicolumn{3}{|c|}{ Blood loss } \\
\hline $10-49 \mathrm{ml}$ & 3 & 0 \\
\hline $50-100 \mathrm{ml}$ & 2 & 0 \\
\hline $101-200 \mathrm{ml}$ & 0 & 3 \\
\hline $201-300 \mathrm{ml}$ & 1 & 3 \\
\hline More than $300 \mathrm{ml}$ & 0 & 2 \\
\hline \multicolumn{3}{|c|}{ Blood transfusion } \\
\hline 0 unit & 17 & 0 \\
\hline 1 unit & 5 & 2 \\
\hline 2 units & 0 & 11 \\
\hline 3 units & 1 & 8 \\
\hline 4 units & 0 & 5 \\
\hline Intraoperative hypotension & 1 & 2 \\
\hline \multicolumn{3}{|c|}{ Postoperative complication } \\
\hline Fever & 2 & 6 \\
\hline Deep vein thrombosis & 1 & 5 \\
\hline \multicolumn{3}{|c|}{ Time required to mobilize } \\
\hline $1^{\text {st }}$ post operative day & 18 & 0 \\
\hline $2^{\text {nd }}$ post operative day & 5 & 1 \\
\hline $3^{\text {rd }}$ post operative day & 0 & 19 \\
\hline $4^{\text {th }}$ post operative day & 0 & 7 \\
\hline \multicolumn{3}{|c|}{ Post operative weight bearing } \\
\hline 1 week & 20 & 0 \\
\hline 2 weeks & 3 & 20 \\
\hline 3 week & 0 & 7 \\
\hline \multicolumn{3}{|c|}{ Post operative full weight bearing } \\
\hline 2 weeks & 17 & 0 \\
\hline 3 weeks & 4 & 1 \\
\hline 4 weeks & 2 & 15 \\
\hline 5 weeks & 0 & 9 \\
\hline 6 weeks & 0 & 2 \\
\hline \multicolumn{3}{|c|}{ Return to activity of daily living } \\
\hline 6 months & 10 & 3 \\
\hline 8 months & 8 & 7 \\
\hline 10 months & 3 & 12 \\
\hline 1 year & 2 & 5 \\
\hline
\end{tabular}


Original Research Article

Table-3: Modified Hip Score evaluation.

\begin{tabular}{|c|c|c|}
\hline SCORE (OUT OF 91) & Proximal Femoral Nail & Dynamic Hip Screw \\
\hline 79 & 0 & 10 \\
\hline 80 & 0 & 6 \\
\hline 81 & 0 & 5 \\
\hline 82 & 0 & 2 \\
\hline 83 & 0 & 2 \\
\hline 84 & 0 & 0 \\
\hline 85 & 3 & 0 \\
\hline 86 & 6 & 0 \\
\hline 87 & 4 & 0 \\
\hline 88 & 5 & 0 \\
\hline 89 & 5 & \\
\hline
\end{tabular}

\section{Discussion}

Intertrochanteric fractures are extracapsular, and thus have a lower propensity to cause interruption of blood supply, but are at risk for displacement. In the elderly population, most of the intertrochanteric fractures occur as the result of a fall. Although these fractures are relatively rare in younger individuals, but may occur in younger age groups due to fall from a height or a motor vehicle collision [9]. Ambulatory patients should be treated aggressively, usually with surgical intervention, with the goal of restoring their level of activity to earlier state as quickly as possible. For nonambulatory patients nonoperative management with good pain control may be the best form of management.

However, conservative management has been seen to be associated with pressure sores, aspiration pneumonia, and many others related to prolonged recumbency \& bed-rest. Making the matters worst were the lost wages, dependency on quality nursing care \& psychosocial impact on the patient. Moreover, patients sustaining intertrochanteric fractures are typically elderly, who are more prone to above mentioned complications. Therefore, we are witnessing a shift from conservative to surgical line of management, which enables early mobilization and return to daily activities of living.

Research over the years led to many refinements in the evolution of implant for osteosynthesis of intertrochanteric fractures. DHS has been in the popular usage since last three decades. Fixation of DHS requires wide surgical exposure as well as involves appreciable blood loss. Complications such as varus collapse, implant cut-out are commonly associated with it. With the passage of time, Gamma nailing gave way to increasing focus on the designing of a nailing construct to address unstable International Journal of Surgery \& Orthopedics fracture patterns as well. Over the recent times, PFN is gaining popularity as it involves minimal surgical exposure \& blood loss. It is also not alien to complications, such as $\mathrm{Z}$ effect (lateral migration of caudal screw, varus collapse and perforation of femoral head by superior screw) \& reverse $\mathrm{Z}$ effect (lateral migration of cephalic screw, varus collapse and femoral head cut-out by inferior screw). Bhakat et al in their study stated less complications in PFN group in comparison to DHS group [10]. In the case series of 400 intertrochanteric fracture patients carried out by Gupta et al, it was found that PFN has better functional outcome with unstable fractures $\&$ requires shorter operation time [11].

The theoretical benefits of intramedullary nails over sideplate devices include improved biomechanics (shortened lever arm), decreased blood loss, smaller incisions, and decreased femoral neck shortening. The largest metaanalysis comparing intramedullary nails with side-plate devices from the Cochrane database concluded that side plates are superior to intramedullary nails in the treatment of intertrochanteric femoral fractures [12]. This metaanalysis, however, included older versions of cephalomedullary nails, which had problems with fracture at the distal tip of the nail. Although this complication does still occur, it is much less frequent with newer nail designs.

There is some evidence in the literature that the functional outcomes in patients with certain fracture types may be influenced by the choice of implant. In a randomized trial by Utrilla etal., there was no overall difference in functional outcomes in patients 65 years of age or older with an intertrochanteric femoral fracture treated with

Available online at: www.surgicalreview.in $88 \mid \mathrm{P}$ a g e 


\section{Original Research Article}

either a Gamma nail or a compression hip screw; however, when patients with unstable fracture patterns were analyzed, those with an intramedullary nail had better walking ability at 12 months than those treated with a compression hip screw [13].

Pajarinen et al. compared outcomes of proximal femoral nailing with compression hip screw fixation in the treatment of intertrochanteric fractures [14]. At 4 months after surgery a much larger percentage of patients $(76 \%)$ treated with intramedullary nail fixation had returned to their preinjury walking ability than patients treated with compression hip screws (54\%). The mean shortening of the femoral neck also was much less in patients treated with intramedullary nail fixation $(1.3 \mathrm{~mm})$ than in those with compression hip screws $(6.1 \mathrm{~mm})$.

Proponents of intramedullary devices contend that the most advantageous aspect of the device is the intramedullary location, which creates a mechanical intramedullary buttress to prevent excessive collapse, making the competence of the lateral cortex nearly irrelevant. In addition, the intramedullary position confers a theoretical biomechanical benefit with a shortened lever arm, which may decrease the fatigue failure rate, especially valuable in fractures with subtrochanteric extension.

Biological and rehabilitation advantages, such as less operative blood loss and decreased injury to the musculature surrounding the hip, are alleged owing to the way these mechanically superior implants can be inserted. Although there is sparse validated information about this advantage, there is equally nothing to refute it.

A limited incision with a starting point at or slightly medial to the tip of the greater trochanter allows sparing of the abductors, facilitates improved rehabilitation, and may cause less postoperative pain.

\section{Conclusion}

Several fixation modalities have been suggested to improve upon the clinical outcome of treatment of intertrochanteric fractures. The minimally-invasive surgical approach without exposing the fracture region causes a minimal soft tissue injury, and decreases the risks of infection; moreover, the advantages of primary haematoma are retained. Therefore, we conclude that PFN is a superior method of osteosynthesis as compared to DHS in the treatment of intertrochanteric fractures.

Conflict of interest: None declared. Funding: Nil, Permission from IRB: Yes

\section{References}

1. Kannus P, Parkkari J, Sievänen H, Heinonen A, Vuori I, Järvinen M. Epidemiology of hip fractures. Bone. 1996;18(1):S57-63.

2. Waters PM, Millis MB. Hip and pelvic injuries in the young athlete. Clinics in sports medicine.1988;7(3): 513-26.

3. Radford P, Needoff M, Webb JK. A prospective randomised comparison of the dynamic hip screw and the gamma locking nail. Bone \& Joint Journal. 1993; 75 (5): 789-93.

4. Bogosavljević M, Stokić D, Friščić Ž, Ristić BM. Unstable intertrochanteric fractures: How to prevent uncontrolled impaction and shortening of the femur. Vojnosanitetski pregled. 2011;68(5):399-404.

5. Streubel PN, Moustoukas MJ, Obremskey WT. Mechanical failure after locking plate fixation of unstable intertrochanteric femur fractures. Journal of orthopaedic trauma. 2013;27(1):22-8.

6. Boyd HB, Griffin LL. Classification and treatment of trochanteric fractures. Archives of Surgery. 1949;58(6) : 853-66.

7. Broos PL, Bisschop AP. Operative treatment of ankle fractures in adults: correlation between types of fracture and final results. Injury. 1991;22(5):403-6.

8. Modified Hip Score. Available http:// www. losangelessportssurgeon. com /pdf/ modified-harris-hipscore. pdf Accessed February 15, 2017.

9. Friedman RJ, Wyman Jr ET. Ipsilateral hip and femoral shaft fractures. Clinical orthopaedics and related research. 1986;208:188-94.

10. Bhakat U, Mukherjee A, Bandyopadhyay R. Comparison between Distractor Application on Both Radial \& Ulnar Side and Radial Side Only for Fracture Distal Radius with Ulnar Styloid Fracture. Open Journal of Orthopedics. 2013;3(05):227.

11. Gupta SV, Valisetti VS. Comparative study between dynamic hip screw vs proximal femoral nailing in intertrochanteric fractures of the femur in adults. International Journal of Orthopaedics. 2015;1(1):07-11.

12. Kurup H, Hossain M, Andrew JG. Dynamic compression plating versus locked intramedullary nailing for humeral shaft fractures in adults. The Cochrane Library. 2011 Jan 1. 


\section{Original Research Article}

13. Utrilla AL, Reig JS, Muñoz FM, Tufanisco CB. Trochanteric gamma nail and compression hip screw for trochanteric fractures: a randomized, prospective, comparative study in 210 elderly patients with a new design of the gamma nail. Journal of orthopaedic trauma. 2005;19(4):229-33.
14. Pajarinen J, Lindahl J, Michelsson O, Savolainen V, Hirvensalo E. Pertrochanteric femoral fractures treated with a dynamic hip screw or a proximal femoral nail. Bone \& Joint Journal. 2005;87(1):76-81.

\section{How to cite this article?}

Samant P.D, Kale S.Y, Singh S.D, Chaudhary P, Dhar S.B, Gohain N.K. Comparison of dynamic hip screw and proximal femoral nail in the treatment of Intertrochanteric fracture of femur. Int $J$ surg Orthopedics 2016;2(4):8590.doi:10.17511/ijoso.2016.i04.06. 